\title{
Elite Young Team Players' Coping, Motivation and Perceived Climate Measures
}

\author{
Géczi Gábor ${ }^{1}$, Vincze Géza ${ }^{2}$, Koltai Miklós² , Bognár \\ József $^{2}$ \\ ${ }^{1}$ Hungarian Ice Hockey Federation, Budapest, Hungary \\ ${ }^{2}$ University, Faculty of Physical Education and Sport Sciences, Budapest
}

\section{KEYWORDS}

\begin{abstract}
The purpose of this study was to compare and contrast coping skills, motivational profiles and perceived climate in elite young ice hockey, soccer, water polo and volleyball players. It was also our aim to examine how male and female athletes differ in the above mentioned psychometric measures. Men's soccer $(n=23)$ and ice hockey $(n=20)$, and also women's volleyball $(\mathrm{n}=15)$ and water polo (13) players ranged in age from 16 to 18 years $(M$ age $=17.17, S D=.85)$. Each team was a finalist in last year's national championship for their age group. The instruments used in this study included the Perceived Motivational Climate in Sport Questionnaire2 (PMCSQ-2), The Sport Motivation Scale (SMS), and the Athletic Coping Skills Inventory-28 (ACSI-28). Cooperative learning does not tend to be high, as one would expect in elite team players. Ice hockey and soccer players usually had higher psychometric measures than water polo and volleyball players. Also, male athletes demonstrate better ACSI-28, PMCSQ-2, and SMS measures than their female counterparts in many of the variables. Amotivation seems to be the most important decisive factor both among team sports and male and female participants. Also, our results prove that there are major differences between young elite male and female team players, so coaches' work in most aspects of their work should be gender-specific. Coaches of youth teams have to understand the motivational factors and coping strategies their athletes demonstrate in order to optimally organize and plan the teaching-learning process in their exercises, especially focus on cooperative task-solving exercises.
\end{abstract}

U18 players, ACSI-28, PMCSQ-2, SMS

\section{Introduction}

Sport psychology researchers have been investigating different means and forms of exercises to better support coaches and scouts in recruitment, talent development (Sands and McNeal 2000), and also to enhance athletic performance (Géczi et al 2008). Most investigations are based on the assumption that psychological characteristics should be considered as important determinants of athletic performance and success (Smith and Christensen 1995). Recently researchers have made an effort to reveal the most relevant psychological characteristics and traits of elite athletes in different sport settings (Smith, Schitz, Smoll and Ptacek 1995). 
According to the literature, becoming a successful athlete requires a high level of persistence, dedication, effort and also a supportive environment from all parties involved (Géczi, Bognár, Tóth, Sipos and Fügedi 2008). Studies comparing and contrasting elite and non-elite athletes found that successful athletes are more committed to their sport (Davis and Mogk 1994), usually set more specific and measurable goals (Goudas, Theodorakis and Karamousalidis 1998, Orlick and Partington 1988), demonstrate a higher concentration level (Goudas, Theodorakis and Karamousalidis 1998, Junge, Dvorak, Rosch, Graf-Baumann, Chomiak and Peterson 2000), a higher confidence level (Gould, Dieffenbach and Moffat 2002), higher coachability (Bebestos and Antonious 2003) and a more stable anxiety level (Kais and Raudsepp 2005) than less successful athletes.

It can be generalized that a high level of worry and anxiety is mostly associated with poor performance and can prevent athletes from performing in their optimal zone (Géczi, Tóth, Sipos, Fügedi, Dancs and Bognár 2008, Hanin 1989, Smith, Smoll and Schitz 1990). It is also reported that cognitive anxiety is negatively related to performance and both too low and too high levels of anxiety cannot lead to optimal performance (Jones 1995).

People with appropriate coping skills can manage stress and adversity with self-confidence; however, people with inadequate coping skills tend to perceive anxiety as a threatening factor (Dolbier, Soderstrom and Steinhardt 2001). Altogether, there seems to be a meaningful association between anxiety, confidence, and coping skills (Cresswell and Hodge 2004, Hammermeister and Burton 2001). In addition, mood, motive for sport involvement, effort investment and coping behaviors are all associated with goal orientation (Newton and Duda 1993, White and Duda 1994).

Motivational profiles are known to have important implications for athletic programs for talent identification and development of the young, skilled athletes (Stewart and Meyers 2004). Frederick and Ryan (1993) found that athletes with a higher level of self-determination and intrinsic motivation have more positive mental characteristics (i.e., lower depression, higher self-esteem, lower anxiety and depression and greater vitality). Most studies agree that intrinsically motivated and task-oriented athletes are more likely to enjoy participating in sport and less likely to drop out (White, Duda, and Keller 1998). Individuals with task orientation tend to believe that success most of all requires effort, intrinsic motivation, and cooperation with peers (Duda and Nicholls 1992). Intrinsically motivated athletes tend to persist at certain activities, select challenging tasks, give effort (Deci, Vallerand, Pelletier and Ryan, 1991, Ferrer-Caja and Weiss 2000) and they are driven by perceived competence, perceived autonomy, goal achievement orientation, and perceived usefulness (Hassandra et al 2003).

Petherick and Weigand (2002) reported that extrinsic motivation is greatly influenced by the climate. Individuals with ego orientation believe that failure is mostly attributed to lack of ability, skill, and effort (Treasure and Roberts 2001). These athletes aim for less challenging tasks, enjoy their sport less (Treasure and Roberts 2001), more extrinsically motivated, which may sooner lead to dropout (Vallerand and Losier 1999). Most studies report that young people with task orientation are more intrinsically motivated and more often experience success than those with ego orientation (Eccles and Wigfield 2002, Ryan and Deci 2000ab).

Researchers support the fact that male and female athletes exhibit similar personality characteristics (Bebestos 2003, Meyers, Bourgeois, LeUnes and Murray 1999). However, according to other studies, male athletes have higher levels of extrinsic motivation than female athletes (Petherick and Weigand 2002), and women tend to experience higher levels of intrinsic motivation than men (Duda, Chi, Newton, Walling and Catley 1995).

It is evident from the literature that the areas of motivation, climate, and coping in elite youth sport have attracted little attention. Water polo, for instance, has not been well researched in sport 
psychology. Some studies were carried out into physiology and body composition (Andreoli, Melchiorri, Volpe, Sardella, Iacopine, De Lorenzo, 2004; Aziz, Lee and The 2002) but there is clearly a lack of research in the field of sport psychology. Also, the number of studies related to success, motivation, and coping in ice hockey is fairly limited (Géczi et al 2008). Soccer and volleyball both suffer from a lack of empirical studies focusing on these psychometric measures.

Water polo, ice hockey, soccer and volleyball are all widely popular sports among young people, so clearly there is a need for empirical research that summarizes the results of multifaceted psychological examinations. According to our understanding, there are very few studies measuring anxiety, coping, and personality factors in a complex way in elite youth team sports. Exploring the complexity of the above mentioned psychological traits of elite young team players may contribute to the appropriate selection, talent development, and also the advancement of specific training methods.

The goal of this study was to compare and contrast elite young team players' coping skills, motivational profiles and perceived climate in ice hockey, soccer, water polo and volleyball. It was also our aim to examine how male and female athletes differ in the above mentioned psychometric measures.

\section{Methods}

In order to facilitate the development of a model for use in youth development programs, this study focuses on elite youth water polo, ice hockey, soccer and volleyball teams and their athletes. Participants for this study were drawn from four different elite U18 athlete populations in Hungary. Altogether four highly popular team sports were selected and all were represented by one of the most successful club teams in the country. Men's soccer $(n=23)$ and ice hockey $(n=20)$, and also women's volleyball $(\mathrm{n}=15)$ and water polo (13) players ranged in age from 16 to 18 years $(M$ age $=17.17$, $S D=.85$ ). Each team was a finalist in last year's national championship for their age group. Participants eligible for this study were those U18 players who had regularly participated in the championship games. All participants and their parents signed an informed consent form highlighting confidentiality and voluntary participation in this study.

\section{Measures}

The instruments used in this study included the Perceived Motivational Climate in Sport Questionnaire-2 (PMCSQ-2), The Sport Motivation Scale (SMS), and the Athletic Coping Skills Inventory-28 (ACSI-28).

\section{Perceived Motivational Climate in Sport Questionnaire (PMCSQ-2)}

PMCSQ-2 was chosen in this study because it allows the researcher to identify how much athletes enjoy their sports and also how they feel about the climate that the coach creates in the exercises (Duda, 1999). The instrument includes the following scales: a) Cooperative learning, b) Important role c) Effort/improvement, d) Punishment for mistakes, c) Unequal recognition, and e) Intra-team member rivalry. Cooperative learning, Important role and Effort/improvement measure the Task-involving climate, moreover Punishment for mistakes, Unequal recognition, and Intra-team member rivalry measure the Ego-involving climate. PMCSQ-2 consists of 33 items using a 5-point Likert-scale $(1=$ Strongly disagree, $2=$ Disagree, $3=$ Neutral, $4=$ Agree, $5=$ Strongly Agree). An Alpha coefficient of 0.87 for Task-involving climate and 0.83 for Ego-involving climate indicate a 
good internal consistency (Seifriz, Duda and Chi 1992). The Hungarian version of PMCSQ-2 has an internal validity of 0.85 for Task and 0.82 for Ego-oriented climate (Révész et al 2008).

\section{Sport Motivation Scale (SMS)}

The 28-item SMS instrument, invented by Pelletier et. al. (1995), measures components of Amotivation, Extrinsic and Intrinsic Motivation. The instrument was constructed of a 7-point Likert Scale ranging from 1 (Does not correspond) to 7 (Corresponds exactly). The Cronbach alpha internal coefficients for the original version ranged between 0.66 to 0.80 (Pelletier, Fortier, Vallerand and Tuson (1995) and it was 0.65 to 0.85 in the Hungarian version of SMS (Tsang, Szabó, Soós and Bute 2005).

Athletic Coping Skills Inventory-28 scoring and reliability

For measuring athletes' coping skills, ACSI-28 was also used in this study (Smith, Schutz, Smoll and Ptacek 1995). ACSI-28 consists of 28 items in seven subscales (Coping With Adversity, Peaking Under Pressure, Goal Setting/Mental Preparation, Concentration, Freedom From Worry, Confidence and Achievement Motivation, and Coachability). ACSI-28 demonstrated a full-scale internal consistency of 0.86 with all subscales ranging from 0.62 to 0.78 (Smith et al 1995). The Hungarian version of ACSI-28 also demonstrates acceptable Cronbach alpha coefficients of 0.61 for Coping with Adversity, 0.84 for Peaking under Pressure, 0.67 for Mental Preparation, 0.64 for Concentration, 0.72 for Freedom from Worry, 0.59 for Confidence and Achievement Motivation, and 0.69 for Coachability (Jelinek 2000).

\section{Data collection and analysis}

At the beginning of the survey, coaches were contacted to enquire whether they were interested in taking part in the survey. Upon receiving a positive answer, U18 players and their parents were also contacted for their written consent. All psychometric instruments were filled out by the eligible players from each team before a training session. A coach and one of the researchers were present during data collection to answer any questions regarding the surveys.

Data analysis was divided into two major sections. The first section includes a detailed description of the sample (Means and Standard Deviations). The second section provided a meaningful tool (ANOVA) for a comparative analysis among the four team sports (Ice hockey, Soccer, Water polo, and Volleyball), and an independent T-test between Male and Female players. After checking for the various assumption of discriminant analysis (normal distribution, correlation, Box's $M$ test), a stepwise discriminant analysis was used to build a predictive model of group membership with team sport and gender as a grouping factor.

\section{RESULTS}

Descriptive measures

In PMCSQ-2 (Table 1), Intra-team member rivalry seems to have a very low result and Effort/improvement quite a high one. Task orientation is a lot higher than Ego orientation measure. Also, there are no statistically meaningful differences among team sports in Cooperative learning. When contrasting the four sports, Ice hockey players demonstrated the lowest Important role, 
Effort/improvement, and Task measures, and the highest levels of Punishment for mistakes, Unequal recognition, Intra-team member rivalry, and Ego orientation. Young elite athletes in soccer on the other hand, had the highest Important role, and also a higher level of Punishment for mistakes, Intrateam member rivalry, and Ego orientation than water polo and volleyball players. Also, soccer players demonstrate higher Task orientation than participants from water polo. Water polo players showed the highest Effort/improvement and Task orientation and lower Punishment for mistakes, Intra-team member rivalry, and Ego orientation than ice hockey and soccer players. In addition, members in the soccer team had lower Unequal recognition measures than in ice hockey. Players in the volleyball team had the lowest levels of Punishment for mistakes, Intra-team member rivalry, and their Ego orientation was lower than ice hockey and soccer players'. Through the comparison of male and female athletes' perceived motivational climate, there were four scales with significant differences. There was no statistical difference between male and female elite players in Cooperative learning, Important role, Effort/improvement, and Task orientation. However, male team players had higher levels of Punishment for mistakes, Unequal recognition, Intra-team member rivalry, and Ego orientation than female athletes.

According to ACSI-28, altogether Freedom from Worry and Coachability have very low levels and both Confidence and achievement motivation and Concentration have high measures (Table 2). Freedom from worry and Confidence and achievement motivation had no significant differences among the team sports. Ice hockey players had the highest Coping with adversity and Concentration level among all the players and they also demonstrate higher Coping with adversity Peaking under pressure and Goal setting/Mental preparation than volleyball players. They also demonstrate lower Coachability than water polo players. Soccer players demonstrate the highest Peaking under pressure and Goal setting/Mental preparation, and higher Coping with adversity and Concentration than volleyball players and lower Coachability levels than water polo players. Water polo players demonstrated the highest Coachability measures, higher Coping with adversity and Goal setting/Mental preparation than volleyball players and lower Peaking under pressure than soccer players. Volleyball players seem to have the lowest measures in all scales. The difference is significant in Coping with adversity, Peaking under pressure, Goal setting/Mental preparation, Concentration, and Coachability. Male and female athletes do not differ in Freedom from worry and Confidence and achievement motivation, however, young elite male athletes seem to have a higher level of Coping with adversity, Peaking under Pressure, Goal setting/Mental preparation, and Concentration than female athletes.

When analyzing the subscales of SMS, one can see a generally low level of Amotivation and relatively high Intrinsic motivation measures (Table 3). There seems to be no statistical difference in Extrinsic motivation among the four team sports' players. Ice hockey players have lower Amotivation than water polo and volleyball players. Soccer players had the lowest Amotivation and the highest Intrinsic motivation in the sample. Water polo players had the highest level of Amotivation and the lowest Intrinsic motivation measures. Participants in the volleyball team have higher Amotivation than ice hockey and soccer, and also lower Amotivation then water polo players. Also, volleyball players demonstrated lower Intrinsic motivation than soccer players. Regarding gender, female athletes had higher Amotivation and lower Intrinsic motivation than their male counterparts. 
Table 1. Descriptive statistics for the subscales of PMCSQ-2

\begin{tabular}{|c|c|c|c|c|c|}
\hline & Mean \pm Std & Team sports & Mean \pm Std & Gender & Mean \pm Std \\
\hline \multirow{4}{*}{$\begin{array}{l}\text { Cooperative } \\
\text { learning }\end{array}$} & \multirow{4}{*}{$16.34 \pm 3.19$} & Ice-hockey & $14.95 \pm 3.77$ & Male & $15.93 \pm 3.51$ \\
\hline & & Soccer & $16.78 \pm 3.10$ & & \\
\hline & & Water polo & $17.46 \pm 2.66$ & Female & $16.96 \pm 2.57$ \\
\hline & & Volleyball & $16.53 \pm 2.50$ & & \\
\hline \multirow[t]{4}{*}{ Important role } & \multirow{4}{*}{$20.66 \pm 2.37$} & Ice-hockey $^{2}$ & $19.70 \pm 2.81$ & Male & $20.81 \pm 2.58$ \\
\hline & & Soccer ${ }^{1}$ & $21.78 \pm 1.95$ & & \\
\hline & & Water polo & $20.69 \pm .85$ & Female & $20.43 \pm 2.02$ \\
\hline & & Volleyball & $20.20 \pm 2.67$ & & \\
\hline \multirow[t]{4}{*}{ Effort/improvement } & \multirow{4}{*}{$35.59 \pm 3.34$} & Ice-hockey $^{3}$ & $34.15 \pm 3.95$ & Male & $35.16 \pm 3.68$ \\
\hline & & Soccer & $36.04 \pm 3.26$ & & \\
\hline & & Water polo ${ }^{1}$ & $37.46 \pm 2.22$ & Female & $36.25 \pm 2.67$ \\
\hline & & Volleyball & $35.20 \pm 2.65$ & & \\
\hline \multirow{4}{*}{$\begin{array}{l}\text { Punishment for } \\
\text { mistakes }\end{array}$} & \multirow{4}{*}{$14.83 \pm 3.84$} & Ice-hockey $^{34}$ & $16.80 \pm 3.79$ & Male * & $16.60 \pm 3.43$ \\
\hline & & Soccer ${ }^{34}$ & $16.43 \pm 3.17$ & & \\
\hline & & Water polo ${ }^{12}$ & $12.38 \pm 3.09$ & Female * & $12.11 \pm 2.67$ \\
\hline & & Volleyball ${ }^{12}$ & $11.87 \pm 2.32$ & & \\
\hline \multirow[t]{4}{*}{ Unequal recognition } & \multirow{4}{*}{$17.87 \pm 6.64$} & Ice-hockey $^{34}$ & $22.20 \pm 6.07$ & Male * & $20.02 \pm 6.70$ \\
\hline & & Soccer & $18.13 \pm 6.77$ & & \\
\hline & & Water polo ${ }^{1}$ & $13.23 \pm 4.47$ & Female * & $14.57 \pm 5.07$ \\
\hline & & Volleyball $^{1}$ & $15.73 \pm 5.41$ & & \\
\hline \multirow{4}{*}{$\begin{array}{l}\text { Intra-team member } \\
\text { rivalry }\end{array}$} & \multirow{4}{*}{$9.71 \pm 2.24$} & Ice-hockey $^{34}$ & $10.40 \pm 1.93$ & Male * & $10.36 \pm 2.21$ \\
\hline & & Soccer ${ }^{34}$ & $10.32 \pm 2.49$ & & \\
\hline & & Water polo ${ }^{12}$ & $8.77 \pm 1.58$ & Female $*$ & $8.75 \pm 1.95$ \\
\hline & & Volleyball $^{12}$ & $8.73 \pm 2.82$ & & \\
\hline \multirow[t]{4}{*}{ TASK } & \multirow{4}{*}{$72.59 \pm 7.69$} & Ice-hockey $^{23}$ & $68.80 \pm 9.27$ & Male & $71.91 \pm 8.76$ \\
\hline & & Soccer ${ }^{1}$ & $74.61 \pm 7.48$ & & \\
\hline & & Water polo ${ }^{1}$ & $75.62 \pm 4.68$ & Female & $73.64 \pm 5.67$ \\
\hline & & Volleyball & $71.93 \pm 6.05$ & & \\
\hline \multirow[t]{4}{*}{ EGO } & \multirow{4}{*}{$42.50 \pm 10.70$} & Ice-hockey $^{34}$ & $49.40 \pm 9.16$ & Male * & $47.21 \pm 10.10$ \\
\hline & & Soccer ${ }^{34}$ & $45.23 \pm 10.69$ & & \\
\hline & & Water polo ${ }^{12}$ & $34.38 \pm 7.22$ & Female * & $35.43 \pm 7.17$ \\
\hline & & Volleyball $^{12}$ & $36.33 \pm 7.25$ & & \\
\hline
\end{tabular}

${ }^{1}$ means significant difference from Ice-Hockey, ${ }^{2}$ means significant difference from Soccer, ${ }^{3}$ means significant difference from Water Polo, ${ }^{4}$ means significant difference from Volleyball; * means significant differences in gender; all at $\mathrm{p}<0.05$ 
Table 2. Descriptive statistics and reliability values for the subscales of ACSI-28-H

\begin{tabular}{|c|c|c|c|c|c|}
\hline & Mean \pm Std & Team sports & Mean \pm Std & Gender & Mean \pm Std \\
\hline \multirow{4}{*}{$\begin{array}{l}\text { Coping with } \\
\text { Adversity }\end{array}$} & \multirow{4}{*}{$11.68 \pm 2.32$} & Ice-hockey $^{4}$ & $12.35 \pm 2.20$ & Male * & $12.16 \pm 1.83$ \\
\hline & & Soccer ${ }^{4}$ & $12.00 \pm 1.47$ & \multirow{3}{*}{ Female * } & \multirow{3}{*}{$10.93 \pm 2.78$} \\
\hline & & Water polo ${ }^{4}$ & $12.00 \pm 2.41$ & & \\
\hline & & Volleyball 1.2 .3 & $10.00 \pm 3.07$ & & \\
\hline \multirow{4}{*}{$\begin{array}{l}\text { Peaking under } \\
\text { Pressure }\end{array}$} & \multirow{4}{*}{$11.79 \pm 2.58$} & Ice-hockey $^{4}$ & $12.80 \pm 2.04$ & \multirow[t]{2}{*}{ Male * } & \multirow[t]{2}{*}{$12.88 \pm 1.73$} \\
\hline & & Soccer ${ }^{3.4}$ & $12.96 \pm 1.46$ & & \\
\hline & & Water polo $^{2}$ & $10.85 \pm 2.76$ & \multirow[t]{2}{*}{ Female * } & \multirow[t]{2}{*}{$10.11 \pm 2.79$} \\
\hline & & Volleyball $^{1.2}$ & $9.47 \pm 2.74$ & & \\
\hline \multirow{4}{*}{$\begin{array}{l}\text { Goal } \\
\text { setting/Mental } \\
\text { Preparation }\end{array}$} & \multirow{4}{*}{$10.23 \pm 1.88$} & Ice-hockey ${ }^{4}$ & $10.45 \pm 2.21$ & \multirow[t]{2}{*}{ Male * } & \multirow[t]{2}{*}{$10.58 \pm 1.94$} \\
\hline & & Soccer ${ }^{4}$ & $10.70 \pm 1.71$ & & \\
\hline & & Water polo ${ }^{4}$ & $10.69 \pm 1.25$ & \multirow[t]{2}{*}{ Female * } & \multirow[t]{2}{*}{$9.68 \pm .167$} \\
\hline & & Volleyball ${ }^{1.2 .3}$ & $8.80 \pm 1.52$ & & \\
\hline \multirow[t]{4}{*}{ Concentration } & \multirow{4}{*}{$12.58 \pm 2.06$} & Ice-hockey ${ }^{4}$ & $13.35 \pm 1.63$ & \multirow[t]{2}{*}{ Male * } & \multirow[t]{2}{*}{$13.21 \pm 1.71$} \\
\hline & & Soccer $^{4}$ & $13.09 \pm 1.80$ & & \\
\hline & & Water polo & $12.31 \pm 2.01$ & \multirow[t]{2}{*}{ Female * } & \multirow[t]{2}{*}{$11.61 \pm 2.21$} \\
\hline & & Volleyball ${ }^{1.2}$ & $11.00 \pm 2.26$ & & \\
\hline \multirow{4}{*}{$\begin{array}{l}\text { Freedom from } \\
\text { Worry }\end{array}$} & \multirow{4}{*}{$7.32 \pm 2.08$} & Ice-hockey & $6.95 \pm 1.87$ & \multirow[t]{2}{*}{ Male } & \multirow[t]{2}{*}{$7.60 \pm 2.00$} \\
\hline & & Soccer & $8.17 \pm 1.96$ & & \\
\hline & & Water polo & $6.92 \pm 1.60$ & \multirow[t]{2}{*}{ Female } & \multirow[t]{2}{*}{$6.89 \pm 2.16$} \\
\hline & & Volleyball & $6.87 \pm 2.61$ & & \\
\hline \multirow{4}{*}{$\begin{array}{l}\text { Confidence and } \\
\text { Achievement } \\
\text { Motivation }\end{array}$} & \multirow{4}{*}{$12.85 \pm 1.90$} & Ice-hockey & $12.85 \pm 1.46$ & \multirow[t]{2}{*}{ Male } & \multirow[t]{2}{*}{$13.16 \pm 1.67$} \\
\hline & & Soccer & $13.43 \pm 1.83$ & & \\
\hline & & Water polo & $12.92 \pm 1.93$ & Female & $12.36 \pm 2.14$ \\
\hline & & Volleyball & $11.87 \pm 2.26$ & & \\
\hline Coachability & & Ice-hockey $^{3}$ & $7.00 \pm 2.47$ & Male & $7.21 \pm 2.32$ \\
\hline & & Soccer $^{3}$ & $7.39 \pm 2.23$ & & \\
\hline & $7.80 \pm 3.17$ & Water polo ${ }^{1.2 .4}$ & $12.00 \pm 1.58$ & Female & $8.71 \pm 4.03$ \\
\hline & & Volleyball $^{3}$ & $5.87 \pm 3.24$ & & \\
\hline
\end{tabular}

${ }^{1}$ means significant difference from Ice-Hockey, ${ }^{2}$ means significant difference from Soccer, ${ }^{3}$ means significant difference from Water Polo, ${ }^{4}$ means significant difference from Volleyball; * means significant differences in gender; all at $\mathrm{p}<0.05$ 
Table 3. Descriptive statistics and reliability values for the subscales of SMS

\begin{tabular}{|c|c|c|c|c|c|}
\hline & Mean \pm Std & Team sports & Mean \pm Std & Gender & Mean \pm Std \\
\hline \multirow[t]{4}{*}{ Amotivation } & \multirow{4}{*}{$9.34 \pm 4.80$} & Ice-hockey ${ }^{3.4}$ & $7.30 \pm 3.93$ & Male * & $6.84 \pm 3.31$ \\
\hline & & Soccer ${ }^{3.4}$ & $6.43 \pm 2.69$ & & \\
\hline & & Water polo ${ }^{1.2 .4}$ & $15.23 \pm .92$ & Female * & $13.18 \pm 4.18$ \\
\hline & & Volleyball ${ }^{1.2 .3}$ & $11.40 \pm 5.06$ & & \\
\hline \multirow{4}{*}{$\begin{array}{l}\text { Extrinsic } \\
\text { motivation }\end{array}$} & \multirow{4}{*}{$57.16 \pm 10.56$} & Ice-hockey & $56.42 \pm 11.58$ & Male & $56.86 \pm 11.89$ \\
\hline & & Soccer & $57.22 \pm 12.40$ & & \\
\hline & & Water polo & $57.69 \pm 7.78$ & Female & $57.61 \pm 8.36$ \\
\hline & & Volleyball & $57.53 \pm 9.11$ & & \\
\hline \multirow{4}{*}{$\begin{array}{l}\text { Intrinsic } \\
\text { motivation }\end{array}$} & \multirow{4}{*}{$67.32 \pm 9.24$} & Ice-hockey & $68.95 \pm 11.55$ & Male * & $69.95 \pm 9.74$ \\
\hline & & Soccer ${ }^{3.4}$ & $70.83 \pm 8.02$ & & \\
\hline & & Water polo ${ }^{2}$ & $63.15 \pm 8.24$ & Female * & $63.29 \pm 6.77$ \\
\hline & & Volleyball $^{2}$ & $63.40 \pm 5.48$ & & \\
\hline
\end{tabular}

\section{Discriminant analysis}

After descriptive statistics and the authors aimed to find out those relevant factors that play an important role in differentiating 1) the teamsports and 2) male and female athletes. The results of discriminant analysis showed that nine variables differentiate the four teamsports in this study in the following order: Amotivation, Coachability, Ego orientation, Important role, Intrinsic motivation, Freedom from worry, Peaking under pressure, Cooperative learning, and Concentration (Table 4). Tables 5 and 6 demonstrate the Eigenvalues and Wilks' Lambda measures and Table 7 shows the classification results for teamsports.

Amotivation, Punishment for mistakes, Ego orientation, Intrinsic motivation, Cooperative learning, Peaking under pressure, and Extrinsic motivation are those factors that differentiate male and female team players in these psychometric measures (Table 8). Tables 9, 10, and 11 show the results of Eigenvalues, Canonical correlations, Wilk's Lambda, Chi square, and Classification results.

Table 4. Discriminant analysis for team sports

\begin{tabular}{|c|c|c|c|c|c|c|c|c|c|c|c|c|c|}
\hline & \multirow{3}{*}{$\begin{array}{l}\text { Entered } \\
\text { Statistic } \\
\text { Statistic }\end{array}$} & \multicolumn{12}{|c|}{ Wilks' Lambda } \\
\hline & & \multirow{2}{*}{$\begin{array}{l}\text { df2 } \\
\text { df2 }\end{array}$} & \multirow{2}{*}{$\begin{array}{l}\text { df } \\
\mathrm{Si}\end{array}$} & \multicolumn{4}{|c|}{ Exact $\mathbf{F}$} & \multicolumn{4}{|c|}{ Approximate F } & \multirow{2}{*}{$\begin{array}{l}\text { Statisti } \\
\text { Statisti }\end{array}$} & \multirow{2}{*}{$\begin{array}{l}\text { df1 } \\
\text { df1 }\end{array}$} \\
\hline & & & & Statisti & df1 & df2 & $\mathbf{S i}$ & Statisti & df1 & df2 & $\mathbf{S i}$ & & \\
\hline 1 & Amotivation & .50 & 1 & 3 & 65.00 & 20.85 & 3 & 65.000 & .00 & & & & \\
\hline 2 & Coachability & .30 & 2 & 3 & 65.00 & 17.08 & 6 & 128.00 & .00 & & & & \\
\hline 3 & EGO & .21 & 3 & 3 & 65.00 & & & & & 14.80 & 9 & 153.47 & .00 \\
\hline 4 & Important role & .19 & 4 & 3 & 65.00 & & & & & 11.66 & 12 & 164.32 & .00 \\
\hline 5 & Intrinsic motivation & .17 & 5 & 3 & 65.00 & & & & & 9.800 & 15 & 168.79 & .00 \\
\hline 6 & Freedom from worry & $.1 \overline{5}$ & 6 & 3 & 65.00 & & & & & 8.682 & 18 & 170.19 & .00 \\
\hline 7 & Peaking under & .14 & 7 & 3 & 65.00 & & & & & 7.673 & 21 & 169.96 & .00 \\
\hline 8 & Cooperative learning & .13 & 8 & 3 & 65.00 & & & & & 6.889 & 24 & 168.81 & .00 \\
\hline 9 & Concentration & .13 & 9 & 3 & 65.00 & & & & & 6.230 & 27 & 167.11 & .00 \\
\hline
\end{tabular}

At each step, the variable that minimizes the overall Wilks' Lambda is entered.

a Maximum number of steps is 36. b Minimum partial $F$ to enter is 1 . c Maximum partial $F$ to remove is 0.

d F level, tolerance, or VIN insufficient for further computation. 
Table 5. Eigenvalues for team sports

\begin{tabular}{lrrrr}
\hline Function & Eigenvalue & \% of Variance & Cumulative \% & Canonical Correlation \\
1 & 2.769 (a) & 76.0 & 76.0 & .857 \\
2 & $.631(\mathrm{a})$ & 17.3 & 93.3 & .622 \\
3 & $.244(\mathrm{a})$ & 6.7 & 100.0 & .443 \\
\hline
\end{tabular}

a First 3 canonical discriminant functions were used in the analysis.

Table 6. Wilks' Lambda for team sports

\begin{tabular}{lcccc}
\hline Test of Function(s) & Wilks' Lambda & Chi-square & df & Sig. \\
1 through 3 & .131 & 125.093 & 27 & .000 \\
2 through 3 & .493 & 43.498 & 16 & .000 \\
3 & .804 & 13.408 & 7 & .063 \\
\hline
\end{tabular}

Table 7. Classification Results $(b, c)$ for team sports

\begin{tabular}{|c|c|c|c|c|c|c|c|}
\hline & & Team sports & Pre & icted Group & Membership & & \\
\hline & & & Ice hockey & Water polo & Volleyball & Soccer & \\
\hline Original & Count & Ice hockey & 11 & 1 & 1 & 7 & 20 \\
\hline & & Water polo & 0 & 13 & 0 & 0 & 13 \\
\hline & & Volleyball & 0 & 1 & 12 & 2 & 15 \\
\hline & & Soccer & 5 & 0 & 2 & 16 & 23 \\
\hline & $\%$ & Ice hockey & 55.0 & 5.0 & 5.0 & 35.0 & 100.0 \\
\hline & & Water polo & .0 & 100.0 & .0 & .0 & 100.0 \\
\hline & & Volleyball & .0 & 6.7 & 80.0 & 13.3 & 100.0 \\
\hline & & Soccer & 21.7 & .0 & 8.7 & 69.6 & 100.0 \\
\hline Cross-validated(a) & Count & Ice hockey & 6 & 1 & 3 & 10 & 20 \\
\hline & & Water polo & 0 & 13 & 0 & 0 & 13 \\
\hline & & Volleyball & 2 & 1 & 10 & 2 & 15 \\
\hline & & Soccer & 6 & 1 & 2 & 14 & 23 \\
\hline & $\%$ & Ice hockey & 30.0 & 5.0 & 15.0 & 50.0 & 100.0 \\
\hline & & Water polo & .0 & 100.0 & .0 & .0 & 100.0 \\
\hline & & Volleyball & 13.3 & 6.7 & 66.7 & 13.3 & 100.0 \\
\hline & & Soccer & 26.1 & 4.3 & 8.7 & 60.9 & 100.0 \\
\hline
\end{tabular}

a Cross validation is done only for those cases in the analysis. In cross validation, each case is classified by the functions derived from all cases other than that case.

b $73.2 \%$ of original grouped cases correctly classified.

c $60.6 \%$ of cross-validated grouped cases correctly classified. 
Table 8. Discriminant analysis for gender

\begin{tabular}{|c|c|c|c|c|c|c|c|c|c|}
\hline \multirow{3}{*}{ Step } & \multirow{3}{*}{ Statistic } & \multicolumn{8}{|c|}{ Wilks' Lambda } \\
\hline & & & & & Exact & & & & \\
\hline & & df2 & Sig. & Statistic & df1 & df2 & Sig. & Statistic & df1 \\
\hline 1 & Amotivation & .577 & 1 & 1 & 67.000 & 49.112 & 1 & 67.000 & .000 \\
\hline 2 & Punishment for mistakes & .417 & 2 & 1 & 67.000 & 46.214 & 2 & 66.000 & .000 \\
\hline 3 & EGO & .398 & 3 & 1 & 67.000 & 32.823 & 3 & 65.000 & .000 \\
\hline 4 & Intrinsic motivation & .375 & 4 & 1 & 67.000 & 26.691 & 4 & 64.000 & .000 \\
\hline 5 & Cooperative learning & .358 & 5 & 1 & 67.000 & 22.595 & 5 & 63.000 & .000 \\
\hline 6 & Peaking under pressure & .350 & 6 & 1 & 67.000 & 19.226 & 6 & 62.000 & .000 \\
\hline & Extrinsic motivation & .343 & 7 & 1 & 67.000 & 16.697 & 7 & 61.000 & .000 \\
\hline
\end{tabular}

At each step, the variable that minimizes the overall Wilks' Lambda is entered.

a Maximum number of steps is 36 .

$\mathrm{b}$ Minimum partial $\mathrm{F}$ to enter is 1 .

c Maximum partial $\mathrm{F}$ to remove is 0 .

d F level, tolerance, or VIN insufficient for further computation.

Table 9. Eigenvalues for gender

\begin{tabular}{lrrrr}
\hline Function & Eigenvalue & \% of Variance & Cumulative \% & Canonical Correlation \\
1 & $1.916(\mathrm{a})$ & 100.0 & 100.0 & .811 \\
\hline
\end{tabular}

a First 1 canonical discriminant functions were used in the analysis.

Table 10. Wilks' Lambda for gender

\begin{tabular}{ccccc}
\hline Test of Function(s) & Wilks' Lambda & Chi-square & df & Sig. \\
1 & .343 & 67.959 & 7 & .000 \\
\hline
\end{tabular}

Table 11: Classification Results(b,c) for gender

\begin{tabular}{lllrrr}
\hline & & \multicolumn{4}{c}{ Predicted Group Membership } \\
Original & Gender & Male & Female & \\
& Count & Male & 40 & 3 & 43 \\
& & Female & 5 & 23 & 28 \\
& $\%$ & Male & 93.0 & 7.0 & 100.0 \\
& & Female & 17.9 & 82.1 & 100.0 \\
\hline Cross-validated(a) & Count & Male & 40 & 3 & 43 \\
& & Female & 5 & 23 & 28 \\
& $\%$ & Male & 93.0 & 7.0 & 100.0 \\
& & Female & 17.9 & 82.1 & 100.0 \\
\hline
\end{tabular}

a Cross validation is done only for those cases in the analysis. In cross validation, each case is classified by the functions derived from all cases other than that case.

b $88.7 \%$ of original grouped cases correctly classified.

c $88.7 \%$ of cross-validated grouped cases correctly classified.

\section{Discussion}

In this paper our goal was to compare and contrast different young elite team players' perceived motivational climate, coping and motivational profiles. It was also our purpose to compare male and female athletes' psychometric measures in these tests. As mentioned earlier, psychological characteristics are considered essential determinants for athletic performance and success (Smith and Christensen 1995). As expected, there were a number of significant differences among the team players. Due to the fact that our sample consisted of young elite athletes from successful teams, the results can be utilized for further improvement in talent care and management.

It is well known that the field of sport is a particularly suitable place for challenge and competence (Larson 2000). The descriptive statistics revealed that ice hockey, soccer, water polo and 
volleyball players demonstrate different motivational and coping measures, and also a different perceived climate. Ice hockey and soccer players usually had higher psychometric measures than water polo and volleyball players, with the exceptions of Cooperative learning, Important role, Effort/improvement, and Task orientation climate. Volleyball players do not seem to demonstrate good coping skills in comparison with other athletes. Interestingly, cooperative learning does not tend to be high, as one would expect in elite team players.

When searching for gender differences, there is a notable finding. Male athletes tend to have a higher level of Punishment for mistakes, Unequal recognition, Intra-team member rivalry, and Ego orientation climate. As demonstrated in the results, male athletes tend to be better at Coping with adversity, Peaking under pressure, Goal setting and mental preparations, and have a higher Concentration level than female athletes. Also, male athletes demonstrate lower Amotivation and higher Intrinsic motivation than female athletes. One might assume that the major differences in the findings among the different sports are accounted for by gender differences.

Contrary to earlier findings (Bebestos and Antonious 2003, Goudas, Theodorakis and Karamousalidis 1998), this paper finds that elite athletes' Goal setting/metal preparation and Coachability in the study do not seem to be at a high level. Low Goal setting/metal preparation can mean that these young elite athletes do not work towards specific performance goals well and do not plan and mentally prepare for their training and games properly. Due to the low level of coachability one can assume that these young elite athletes may not be open enough for coaches instruction and constructive criticism. Also, according to earlier research studies (Gould, Dieffenbach and Moffat, 2002, Junge, Dvorak, Rosch, Graf-Baumann, Chomiak and Peterson 2000), this paper proves that elite athletes demonstrate a high concentration level and a high confidence level. The findings of this study could not prove that a high level of worry negatively influences athletes' overall performance (Martens, Vealey and Burton 1990). Freedom from worry is generally low in this sample.

Csíkszentmihályi indicated that individuals are intrinsically motivated when the level of task challenge is suited to one's skills. Anxiety occurs when the challenge is greater than the skills, and if skills exceed challenge, boredom is the likely outcome (Csíkszentmihályi 1975). Hence, coaches need to focus on creating a climate, and plan for individually challenging exercises where their athletes are intrinsically motivated.

Players in this study can be considered intrinsically motivated and task oriented, which may be a reason for their successes (White, Duda, and Keller 1998). Intrinsic motivation and task orientation seem to have a more important role in the success than Goal setting, Freedom from worry and Coachability.

Both discriminant analyses show that Amotivation is the most important decisive factor. Besides Amotivation, Ego orientation, Intrinsic motivation, Peaking under pressure, Cooperative learning are all decisive factors when distinguishing among the team sports and also between male and female athletes. When distinguishing among team sports, there are nine steps (Amotivation, Coachability, Ego, Important role, Intrinsic motivation, Freedom from worry, Peaking under pressure, Cooperative learning, and Concentration) showing a meaningful differentiating impact. When distinguishing between male and female athletes, there are seven scales (Amotivation, Punishment for mistakes, Ego, Intrinsic motivation, Cooperative learning, Peaking under pressure, and Extrinsic motivation) causing statistical difference between genders. 


\section{Conclusion}

There seems to be a major difference among the team sports with regard to the U18 age players' psychometric measures. Coaches of youth teams have to understand the motivational factors and coping strategies their athletes demonstrate in order to optimally organize and plan the teachinglearning process in their exercises, especially focusing on cooperative task-solving exercises. Also, our results prove that there are major differences between young elite male and female team players, so most aspects of coaches' work should be gender-specific.

\section{REFERENCES}

Andreoli, A., Melchiorri, G., Volpe, S. L., Sardella, F., Iacopine, L., \& De Lorenzo, A. (2004). Multicompartment model to assess body composition in professional water polo players. Journal of Sport Science and Medicine, 44, 38-43.

Aziz, A. R., Lee, H. C., \& Teh, K. C. (2002). Physiological characteristics of Singapore national water polo team players. Journal of Sport Science and Medicine, 24, 315-9.

Bebestos, E. \& Antonious, P. (2003). Psychological skills of Greek badminton athletes. Perceptual and Motor Skills, 97, 1289-1296.

Cresswell, S. \& Hodge, K. (2004). Coping skills: Role of trait sport confidence and trait anxiety. Perceptual and Motor Skills, 93, 433-438.

Csíkszentmihályi, M. (1975). Beyond boredom and anxity. San Francisco: Jossey-Bass.

Davis, C. \& Mogk, J. P. (1994). Some personality correlates of interest and excellence in sport. International Journal of Sport Psychology, 25, 131-143.

Deci, E. L., Vallerand, R. J., Pelletier, L. G., \& Ryan, R. M. (1991) Motivation and education: The selfdetermination perspective. Educational Psychologist, 26, 325-346.

Dolbier, C., Soderstrom, M. \& Steinhardt, M. (2001). The relationship between self-leadership and enhanced psychological health and work outcomes. The Journal of Psychology, 5, 469-485.

Duda, J., Chi, L., Newton, M., Walling, M., \& Catley, D. (1995). Task and ego orientation and intrinsic motivation in sport. International Journal of Sport Psychology, 26, 40-63.

Duda, J. L. \& Nicholls, J. G. (1992). Dimensions of achievement motivation in schoolwork and sport. Journal of Educational Psychology, 84, 290-299.

Eccles, J. S. \& Wigfield, A. (2002). Motivational beliefs, values, and goals. Annual Review of Psychology, 53, 109-132.

Ferrer-Caja, E. \& Weiss, M. R. (2000). Predictors of intrinsic motivation among adolescent student in physical education. Research Quarterly for Exercise and Sport, 71, 267-279.

Frederick, C. \& Ryan, R. (1993). Differences in motivation for sport and exercise and their relations with participation and mental health. Journal of Sport Behavior, 16, 124-146.

Géczi, G., Bognár, J., Tóth, L., Sipos, K., \& Fügedi, B. (2008). Competitive State Anxiety (Csai-2-H), Athletic Coping Strategies (Acsi-28-H), And State-Trait Personality Inventory (Stpi-Y-H) Of Different Age Groups Of Hungarian National Ice Hockey Players. International Sport Science and Coaching, 2, 277-285.

Géczi, L., Tóth, L., Sipos, K., Fügedi, B., Dancs, H., \& Bognár, J. (2008). Examination of Competitive State Anxiety, Athletic Coping Skills and Personality in young elite Hungarian National Ice Hockey Players., Kinesiology, in press.

Goudas, M. Theodorakis, Y., \& Karamousalidis, G. (1998). Psychological skills in basketball: Preliminary study for development of a Greek form of the ACSI-28. Perceptual and Motor Skills, 86, 59-65.

Gould, D., Dieffenbach, K., \& Moffett, A. (2002). Psychological characteristics and their development in Olympic champions. Journal of Applied Psychology, 3, 172-204. 
Hammermeister, J. \& Burton, D (2001). Stress, appraisal, and coping revisited: Examining the antecedents of competitive state anxiety with endurance athletes. The Sport Psychologist, 15, 66-90.

Hanin, Y. L. (1989). Interpersonal and intragroup anxiety in sports. In: Anxiety in sports. An international perspective. Ed: Hackfort, D. \& Spielberger, C.D. New York: Hemisphere Publ, p. 19-38.

Hassandra, M., Goudas, M., \& Chroni, S. (2003). Examining the factors associated with intrinsic motivation in physical education: A qualitative approach. Psychology of Sport and Exercise, 4, 211-223.

Jelinek, Z. (2000). The personality correlates of the physical vulnerability in sports. MSc thesis, Budapest: University of Eötvös Loránd.

Jones, G. (1995). More than just a game: research developments and issues in competitive anxiety in sport. British Journal of Psychology, 86, 449-478.

Junge, A. Dvorak, J. Rosch, D., Graf-Baumann, T., Chomiak, J., \& Peterson, L. (2000). Psychologal and sportspecific characteristics of football players. The American Journal of Sport Medicine, 28(59), S22-28.

Kais, K., Raudsepp, L. (2005) Intensity and direction of competitive state anxiety, self-confidence and athletic performance. Kinesiology, 1, 13-20.

Larson, R.W. (2000). Toward a psychology of positive youth development. American Psychologist, 55, $170-183$.

Martens, R., Vealey, R. S., \& Burton, D. (1990). Competitive Anxiety in Sport. Champaign, IL: Human Kinetics Books.

Meyers, M. C., Bourgeois, A. E., LeUnes, A., \& Murray, N. G. (1999). Mood and psychological skills of elite and sub-elite equestrian athletes. Journal of Sport Behavior, 3, 399-409.

Murica, J. A. M., Gimeno, E. C., \& Coll, D. G. (2007). Young athletes' motivational profiles. Journal of Sport Science and Medicine, 6, 172-179.

Newton, M. L. \& Duda, J. L. (1993). Elite adolescent athletes' achievement goals and beliefs concerning success in tennis. Journal of Sport and Exercised Psychology, 15, 437-448.

Orlick, T. \& Partington, J. (1988). Mental links to excellence. Sport Psychologist, 2, 105-130.

Pelletier, L. G., Fortier, M. S., Vallerand, R. J., Tuson, K. M., Briere, N. M., \& Blais, M. R. (1995). Toward a New Measure of Intrinsic Motivation, Extrinsic Motivation and Amotivation in Sports: The Sport Motivation Scale (SMS). Journal of Sport \& Exercise Psychology, 1, 35-53.

Petherick, C., \& Weigand, D. (2002). The relationship of dispositional goal orientations and perceived motivational climates on indices of motivation in male and female swimmers. International Journal of Sport Psychology, 33, 218-237.

Révész L., Bognár J., Trzaskoma-Bicsérdy G., \& Kovács T. L. (2008). Validation of the Perceived Motivational Climate in Sport Questionnaire-2 (PMCSQ-2). Kalokagathia, in press (In Hungarian: English abstract).

Ryan, R. M. \& Deci, E. L. (2000a). Intrinsic and extrinsic motivation: Classic definitions and new directions. Contemporary Educational Psychology, 25, 54-67.

Ryan, R. M. \& Deci, E. L. (2000b). Self-determination theory and the facilitation of intrinsic motivation, social development, and well-being, American Psychologist, 55, 68-78.

Sands, W. A. \& McNeal, J. R. (2000). Predicting athlete preparation and performance: A theoretical perspective. Journal of Sport Behavior, 3, 289-300.

Smith, R., Smoll, F., \& Schutz, R. (1990). Measurement and correlates of sport-specific cognitive and somatic trait anxiety: The Sport Anxiety Scale. Anxiety Research, 2, 263-280.

Smith, R. E., Schitz, R. W., Smoll, F. L., \& Ptacek, J. T. (1995). Development and validation of a multidimensional measure of sport-specific psychological skills: The athletic coping skills inventory-28. Journal of Sport \& Exercise Psychology, 17, 379-398.

Stewart, C. \& Meyers, M. C. (2004). Motivational Traits of Elite Young Soccer Players. Physical Educator, 4, 213-218.

Tillman, M. D., Hass, C. J., Brunt, D., \& Bennett, G. R. (2004). Jumping and landing techniques in elite women's volleyball. Journal of Sport Science and Medicine, 3, 30-36. 
Treasure, D. C., Roberts, G. C. (2001). Students' perceptions of the motivational climate, achievement beliefs, and satisfaction in physical education. Research Quarterly for Exercise and Sport, 72, 165-175.

Vallerand, R. J., Losier, G. F. (1999). An integrative analysis of intrinsic and extrinsic motivation in sport. Journal of Applied Sport Psychology, 11, 142-169.

White, S. A., Duda, J. L. (1994). The relationship of gender, level of sport involvement, and participation motivation to task and ego orientation. International Journal of Sport Psychology, 25, 4-18.

White, S. A., Duda, J. L., Keller, M. R. (1998). The relationship between goal orientation and perceived purposes of sport among youth sport participants. Journal of Sport Behavior, 21, 4, 474-483. 